UNITED STATES

DEPARTMENT OF THE INTERIOR

GEOLOGICAL SURVEY

MATHEMATICAL MODEL OF GAMMA-RAY SPECTROMETRY BOREHOLE LOGGING

FOR QUANTITATIVE ANALYSIS

By U1rich Schimschal

Open-File Report $81-402$

Denver, Colorado

1981 


\section{UNITED STATES DEPARTMENT OF THE INTERIOR \\ JAMES G.WATT, Secretary \\ GEOLOGICAL SURVEY}

Doyle G. Frederick, Acting Director

For additional information write to:

U.S. Geological Survey

Water Resources Division

Mail Stop 403, Box 25046

Denver Federal Center

Denver, Colorado 80225

For purchase, write to:

Open File Services Section

U.S. Geological Survey

Box 25425

Denver Federal Center

Denver, Colorado 80225

(303) 234-5888; FTS 234-5888 
CONTENTS

Page

Abstract-1- 1

Introduction- 1

Description of the mathematical model- 2

Description of the computer program- 6

Conclusions- 9

References cited-1- 9

\section{ILLUSTRATIONS}

Figure 1. Diagram of the theoretical model used to calculate various effects in gamma-spectral logging- 3

2. General flow chart for program MODEL- 7

\section{TABLES}

Table 1. Program input parameters and description-_ 10

2. Program listing- 11 


\title{
MATHEMATICAL MODEL OF GAMMA-RAY SPECTROMETRY BOREHOLE \\ LOGGING FOR QUANTITATIVE ANALYSIS
}

By

Ulrich Schimschal

\begin{abstract}
A technique for analyzing gamma-ray spectral-logging data has been developed, in which a digital computer is used to calculate the effects of gamma-ray attenuation in a borehole environment. The computer model allows for the calculation of the effects of lithology, porosity, density, and the thickness of a horizontal layer of uniformly distributed radioactive material surrounding a centralized probe in a cylindrical borehole. The computer program also contains parameters for the calculation of the effects of well casing, drilling fluid, probe housing, and losses through the sodium-iodide crystal. Errors associated with the commonly used mathematical assumption of a point detector are eliminated in this model.
\end{abstract}

\section{INTRODUCTION}

A technique for analyzing gamma-ray spectral-logging data can be used quantitatively to determine specific activities of radioactive materials emitting gamma radiation. The computer program described in this manuscript is intended to permit the inclusion of numerous parameters pertinent to actual onsite conditions; therefore, it is essential that a thorough investigation be undertaken to obtain the necessary program input parameters with reasonable precision. Attenuation parameters for gamma radiation in 
natural materials are not always easily available; however, relatively simple laboratory procedures permit parameters of gamma-ray attenuation to be measured at the desired energy levels. The theoretical model calculates a single horizontal layer for a given distance from the center of the probe. More complex models represented by a series of layers of different concentrations of radioactive materials, needs to be calculated one layer at a time. The program, written for the PDP $11 / 20$ computer, $1 /$ requires 2 hours of computer time for a given single-layer case. Using an existing centralized-probe model significantly reduces computer time required for numerical integration. Because numerical integration is rather time consuming, the development of a decentralized model has been deferred until access is available to a high-speed computer system.

DESCRIPTION OF THE MATHEMATICAL MODEL

The program was developed primarily to study a variety of effects in the borehole environment. Experimentation with the various effects of crystal, probe design, and borehole environment gradually led to the development of a mathematical model that could explain these experimental observations. The mathematical model and the various parameters that have been included in the program are depicted in figure 1. For a discussion of the theory of gammaray attenuation in boreholes, see Barsukov and others (1965). The theoretical details concerning attenuation effects in cylindrical crystal detectors can be found in Schimschal (1980a). Interpretation procedures making use of the program can be found in Schimschal (1980b).

$1 /$ The use of brand names in this report is for identification only and does not imply endorsement by the U.S. Geological Survey. 


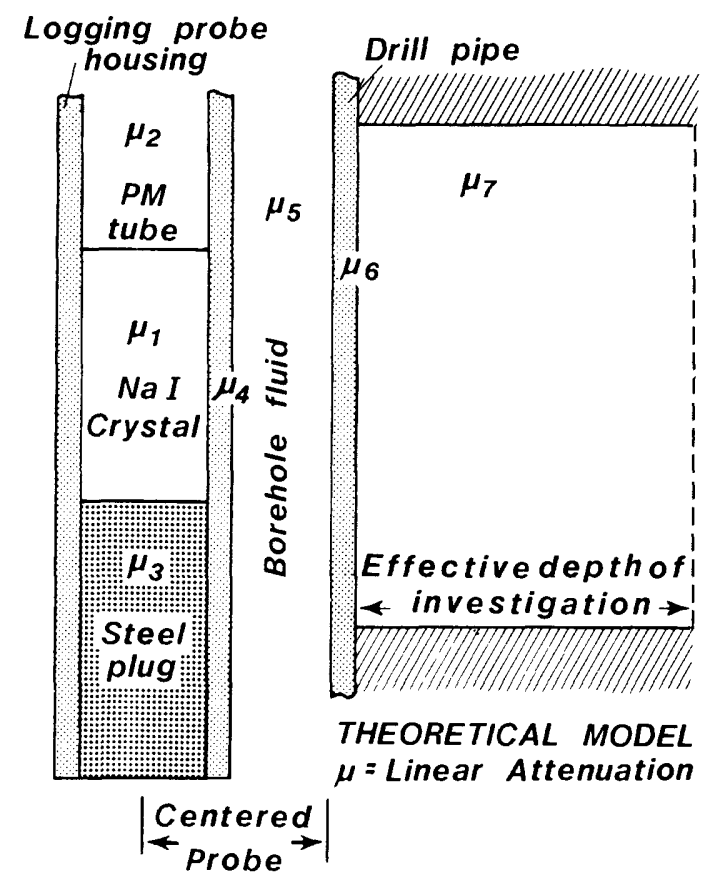

Figure 1.-- Theoretical model used to calculate various effects in gamma-spectral logging. 
The probe is centered in the borehole. This is accomplished easily with the use of standard centralizers. Linear-attenuation effects of the probe have been divided into: (1) Absorbed fraction of radiation on the crystal $\left(\mu_{1}\right)$; (2) effects of the inside part of the probe above the crystal ( $\left.\mu_{2}\right)$; (3) effects of the steel plug below the crystal $\left(\mu_{3}\right)$; and (4) effects of the housing $\left(\mu_{4}\right)$. Because only part of the radiation incident on the crystal is absorbed, only the absorbed fraction of the radiation is considered. It is assumed that no upper limit exists on the photomultiplier tube, and the lower limit of the steel plug extends to infinity (to avoid additional mathematical complexity). Losses in the borehole fluid $\left(\mu_{5}\right)$ may be sizeable at low energy levels and are accounted for by the program. If logging above the water table, the attenuation coefficient for air is substituted. In nuclear-waste disposal applications for which the program was developed, contaminated areas generally are closed off by the well casing, and the attenuation for the casing $\left(\mu_{6}\right)$ needs to be accounted for. Provision was made in the program to incorporate all these effects. For applications in uncased holes, parameter $\mu_{6}$ is set equal to that of the borehole fluid or air. The model does not account for radioactive contamination of the borehole fluid.

Radioactive contamination in this model is assumed to be distributed uniformly in a horizontal layer surrounding the borehole. This layer can be calculated in any chosen position relative to the coordinate system, which in turn is centered in the cylindrical crystal. The layer thickness is not restricted, and any thickness can be used to calculate effects of beds thinner than the length of the crystal. The effective depth of investigation of the probe is a program parameter of relative importance. Because for any given 
material the contribution to the total radiation received at the crystal also is a function of the material attenuation $\left(\mu_{7}\right)$ of the radioactively contaminated layer, at some distance in the formation a depth exists beyond which no further significant contribution can be expected. This distance, the effective depth of investigation, is a function of the material and desired mathematical accuracy. This effective depth of investigation can be established in two ways: (1) From simpler closed-form point-detector solutions of borehole models, or (2) from increasing the radius of the effective layer to the point where numerical integration of the model leads to insignificant change in the final result. Study of these two approaches indicates that, for borehole applications, the depth of investigation ranges from 60 to $100 \mathrm{~cm}$ (centimeters). The most difficult parameter to establish for this program is that of the linear attenuation $\left(\mu_{7}\right)$ of the material in the horizontal layer. This attenuation depends on the density and chemical composition of the contaminated rock, and also on its porosity and water saturation. Values for some common materials, which depend on the energy level of a desired peak in the energy spectrum, can be found in the Radiological Health Handbook of the U.S. Department of Health, Education, and Welfare (1970). For common rock types, however, no values are listed. Those given for concrete or quartz can be used to approximate borehole 1ithology. Experimentation can quickly and inexpensively determine these attenuation values for given type 1ithologies. (For a discussion on interpretive procedures see Schimscha1, 1980b.) 


\section{DESCRIPTION OF THE COMPUTER PROGRAM}

Numerical integration usually is time-consuming; therefore, the program needs to be a compromise between computer time and sufficient mathematical accuracy. The theory in the program requires that the radioactively contaminated layer be divided into small volume elements that can be approximated by point sources. A minimum number of volume elements requires 15 by 15 intervals for numerical integration; which results in an error of less than 5 percent. For larger computers, 25 by 25 intervals may be used. The division into volume elements is governed by the program parameters.

The number of volume elements, KMAXX and MMAXX, are incorporated as fixed parameters into the main program. The effect on the detector of each of these point sources or volume elements is then calculated by integrating or summing up radiation incident onto and exiting the area elements into which the crystal surface has been divided. Numerical experimentation with integration over the crystal surface showed that a compromise solution could be obtained requiring a minimum of 30 by 30 intervals. The number of intervals, NMAX and MMAX, were incorporated as fixed parameters into subroutines SUM2D1, SUM2D, and SUM3D (see flowchart, fig. 2).

The main program reads the input, calculates the numerical integration of the volume elements of the radioactive layer surrounding the borehole, and prints the output. The effects of the probe, the borehole, and well casing are computed by the subroutines INT2D and DETECT, both called from the main program.

Subroutine INT2D calculates radiation incident on the cylindrical surface of a scintillation crystal from a given radioactive point source at an arbitrary location outside the crystal. Incidence on the flat end surfaces of the 


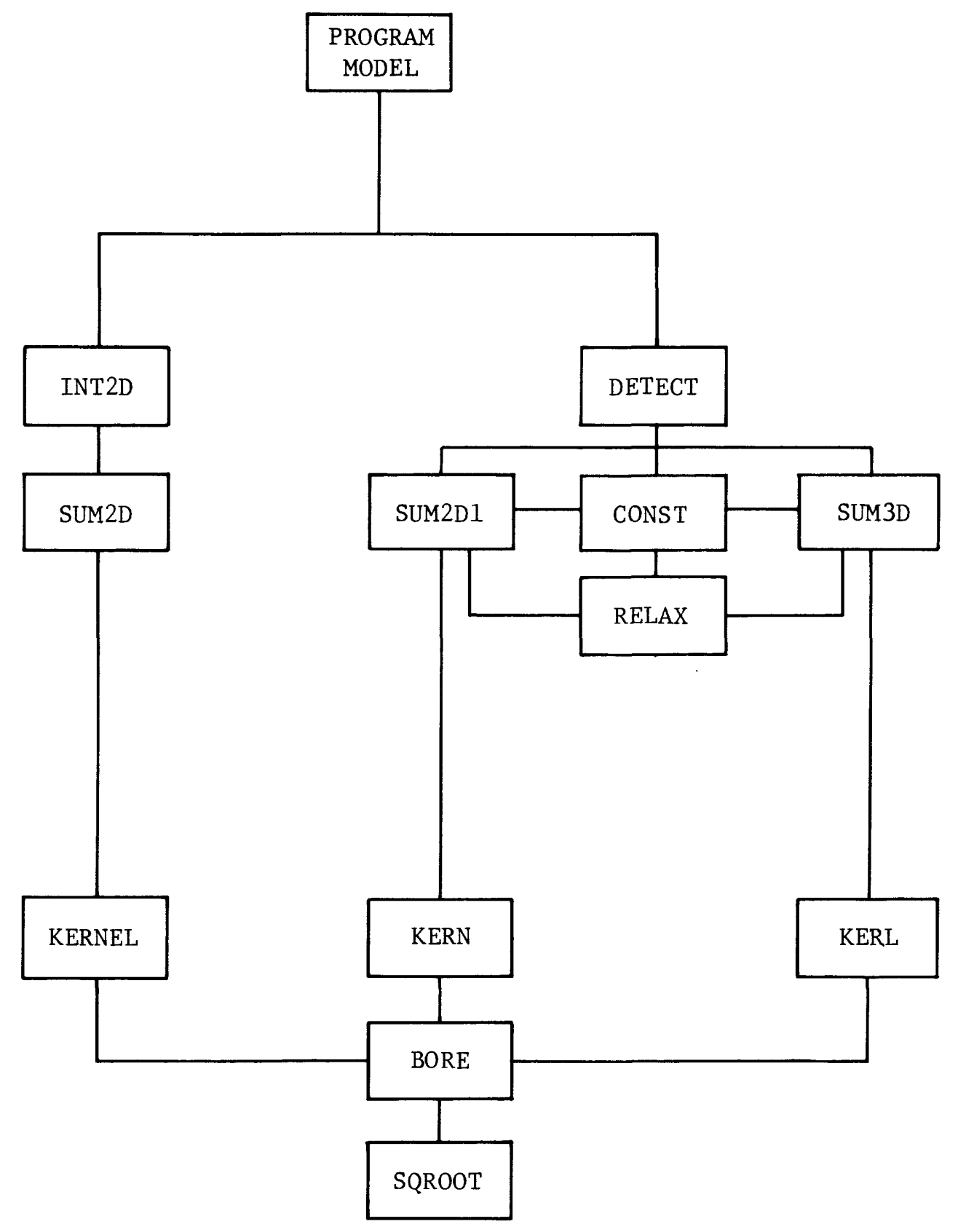

Figure 2.--General flowchart for program MODEL. 
cylindrical detector is not calculated by this subroutine. The amount of surface area exposed to the radiation from a point source also is calculated in subroutine INT2D. Subroutine INT2D accomplishes the numerical integration over the exposed surface area by calling on subroutine SUM2D. This latter subroutine generates the intervals necessary for the surface integration, sums the surface elements, and in turn calls on subroutine KERNEL, where the exponential attenuation or integrand for a given ray path from source to surface element is calculated. Corrections for housing, borehole, and casing are calculated in subroutine BORE, which is called from subroutine KERNEL. From subroutine KERNEL, the program calls for subroutine SQROOT. This subroutine accomplishes the calculation of a square root, and the choice of a proper solution.

Subroutine DETECT calls on subroutine SUM2D1 and its subroutines to ca1culate the amount of radiation emerging from the scintillation detector crystal at the cylindrical surface, after partial absorption by the crystal. Then subroutine DETECT calls on SUM3D and its subroutines CONST, RELAX and KERL to calculate the effects of radiation incident on both the flat ends of the crystal. The angle subtended by radiation incident on the crystal is also calculated in subroutine DETECT.

Subroutine SUM2D1 performs an integration over the cylindrical part of the crystal. It calls upon subroutines CONST, RELAX, and KERN. Subroutine CONST calculates the coefficients for a quartic equation. Subroutine RELAX solves the quartic equation by successive approximation. This subroutine was introduced after it was discovered that the closed form solution for the quartic equation proved unreliable for values approaching zero. The results of subroutine RELAX are used to calculate the exponential attenuation in subroutine 
KERN. In addition, information generated by subroutines BORE and SQROOT are entered into KERN (as described before for subroutine KERNEL). Input into SUM3D is identical to that described above for subroutine SUM2D1 (see fig. 2).

\section{CONCLUSIONS}

The program has been successful in quantifying a great many parameters that cannot be established in existing test pits. It supersedes theoretical approaches based on point or line detectors, and gives the practicing log analyst a tool for modelling gamma-ray borehole measurements and for assessing changes in the borehole environment. The program results compare favorably with test-pit and laboratory results (Schimschal, 1980b).

Program input parameters and their descriptions follow in table 1. Computer printouts of the program listing follow in table 2 .

\section{REFERENCES CITED}

Barsukov, 0. A., and others, 1965, Radioactive investigations of oil and gas wells: New York, Pergamon Press, 289 p.

Bureau of Radiological Health and Training Institute Environmental Control Administration, 1970, Radiological health handbook: U.S. Department of Health, Education, and Velfare, Public Health Service, 458 p.

Schimschal, Ulrich, 1980a, Scintillation detectors in gamma spectral logging; geometry, absorption, and calibration: U.S. Geological Survey Open-File Report 80-688, 29 p. 1980b, Quantitative effects of lithology, borehole environment, and probe design in gamma spectral logging with scintillation crystals: The Log Analyst, v. 21, no. 5, p. 3-10. 
Table 1.--Program input parameter and description

IThe output is given in terms of a geometric

coefficient for unit source activity.]

$H \quad$ Length of crystal, in centimeters.

D Crystal diameter, in centimeters.

XMU Linear attenuation of radioactive layer per centimeter.

XMUD Linear attenuation coefficient of crystal per centimeter.

XMUL Linear attenuation coefficient of space above crystal per centimeter.

XMU2 Linear attenuation coefficient of steel plug per centimeter.

T1 Thickness of probe housing, in centimeters.

T2 Thickness of borehole fluid layer, in centimeters.

T3 Thickness of well casing, in centimeters.

U. Linear attenuation of probe housing per centimeter.

U2 Linear attenuation of borehole fluid per centimeter.

U3 Linear attenuation of well casing per centimeter.

ZZ1 Lower boundary of radioactive layer from the center of the crystal, in centimeters.

ZZ2 Upper boundary of radioactive layer from the center of the crystal, in centimeters.

RR1 Closest radius of radioactive layer from the axis of the crystal, in centimeters.

RR2 Effective radius from the axis of the crystal, in centimeters.

INPUT FORMAT F(IX, 7.2)

Order in which parameters are 1isted: H, D, T1, T2, T3, ZZ1, ZZ2, RR1, RR2, XMU, XMUD, XMU1, XMU2, U1, U2, U3.

Example of input and output:

Input:
R PIP
*TT: =RK2:MODIN.DAT
5.08
3.18
0.26
1.25
0.56
0.0
15.5
3.66
13.66
0.1
0.18
0.03
0.38
.38
0.06
0.08
$* \quad$

Output:

RUN RK2:MOD

*RK2:MODIN.DAT

$\mathrm{XMU}=0.100000 \mathrm{E}+00 \quad \mathrm{XMUD}=0.180000 \mathrm{E}+00$

$\mathrm{H}=0.508000 \mathrm{E}+01 \mathrm{D}=0.318000 \mathrm{E}+01$

SUM $=0.127 \mathrm{E}+02$ 

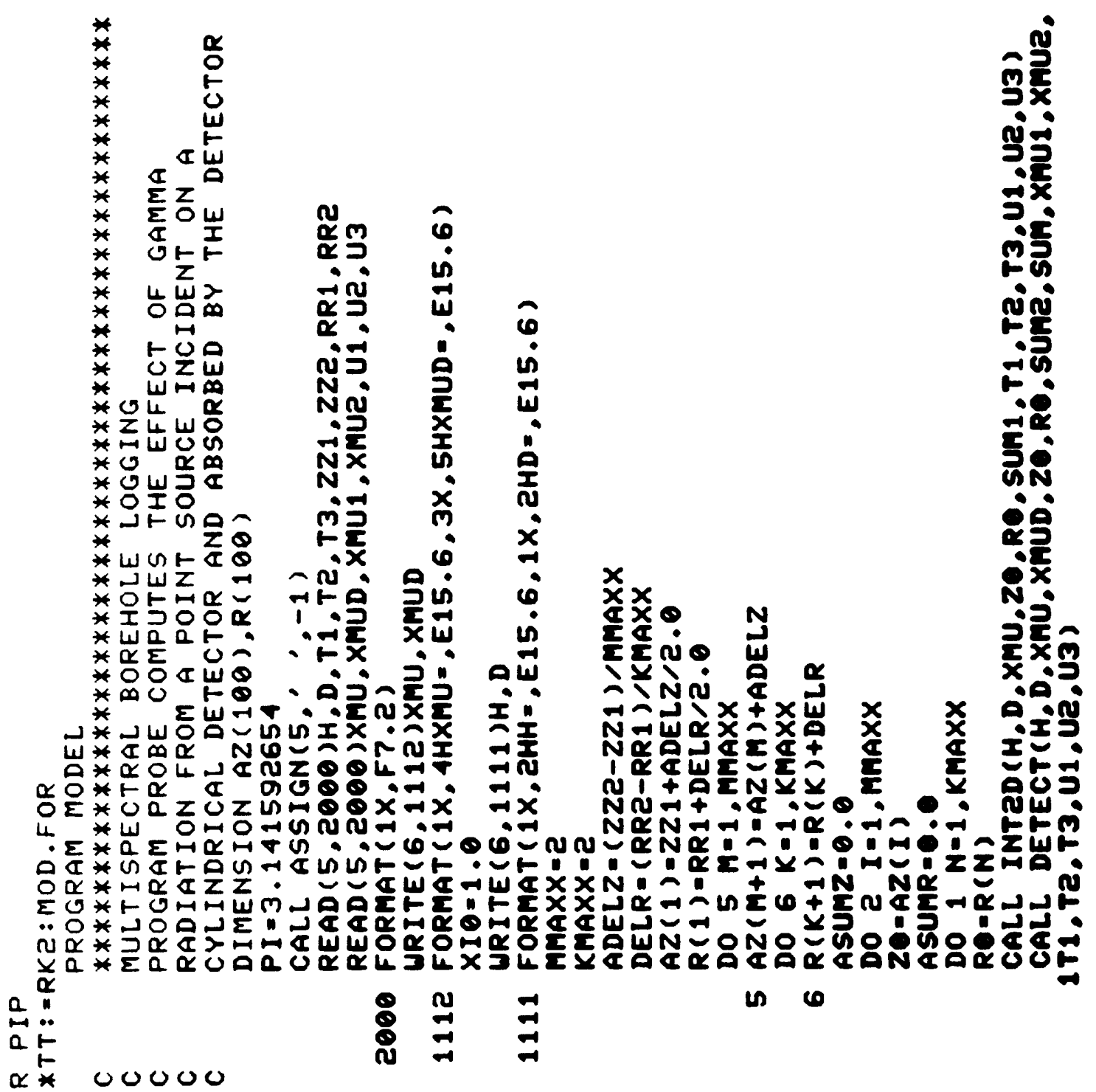

in 6 


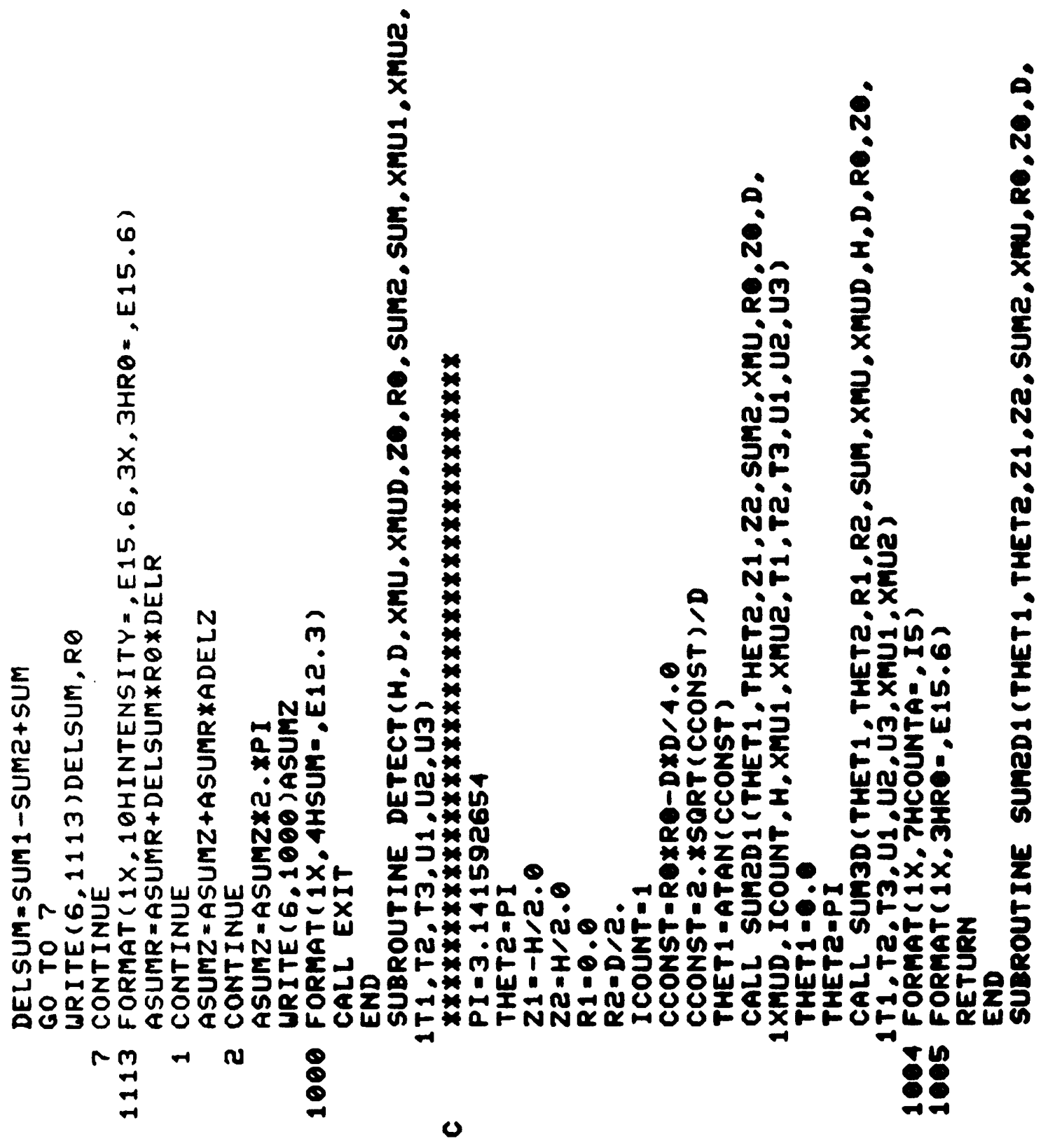




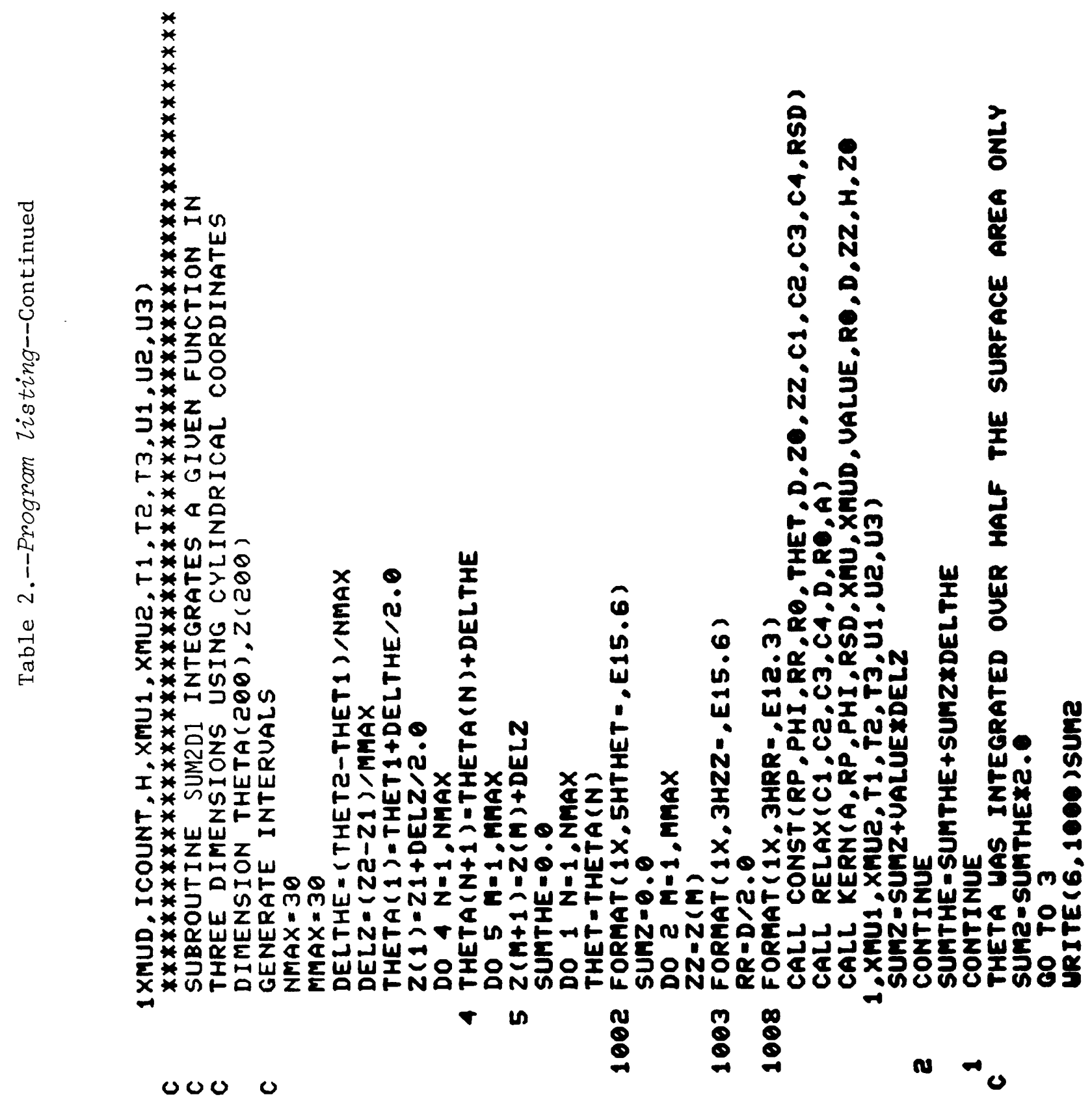




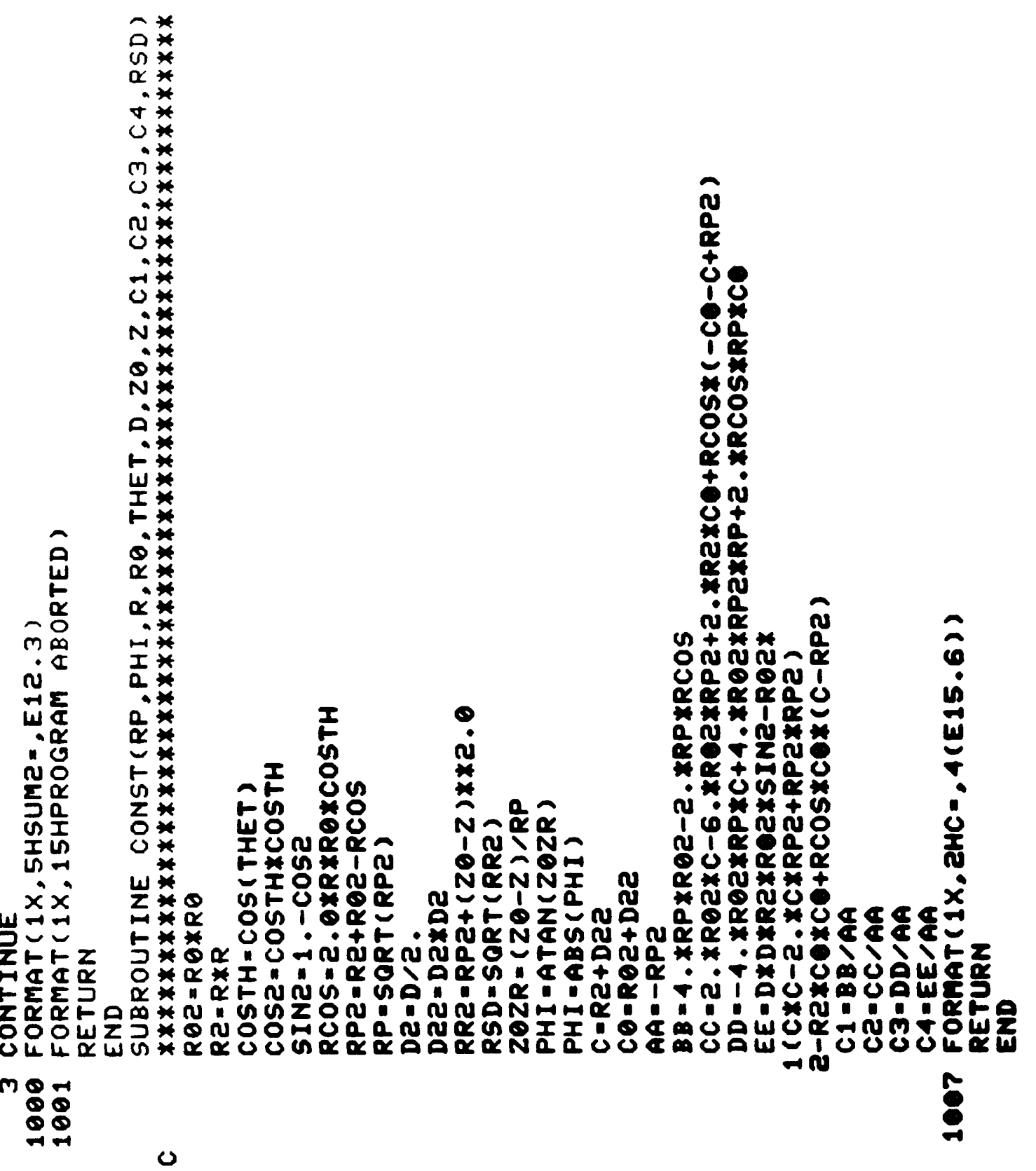



유군

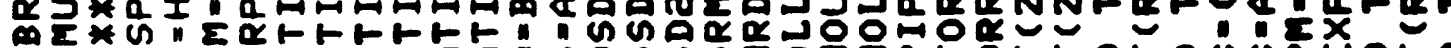

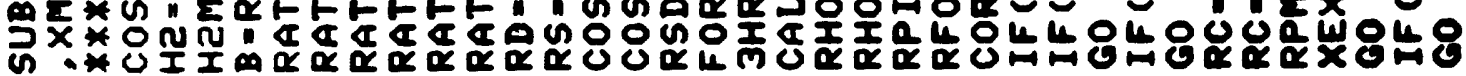

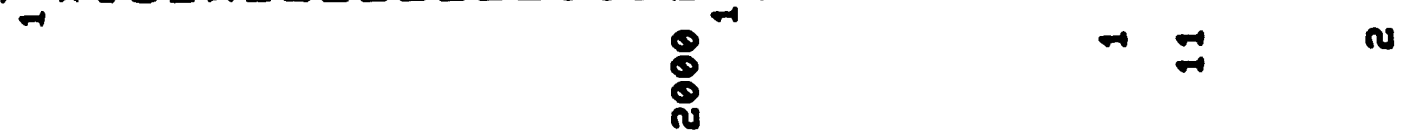

0 


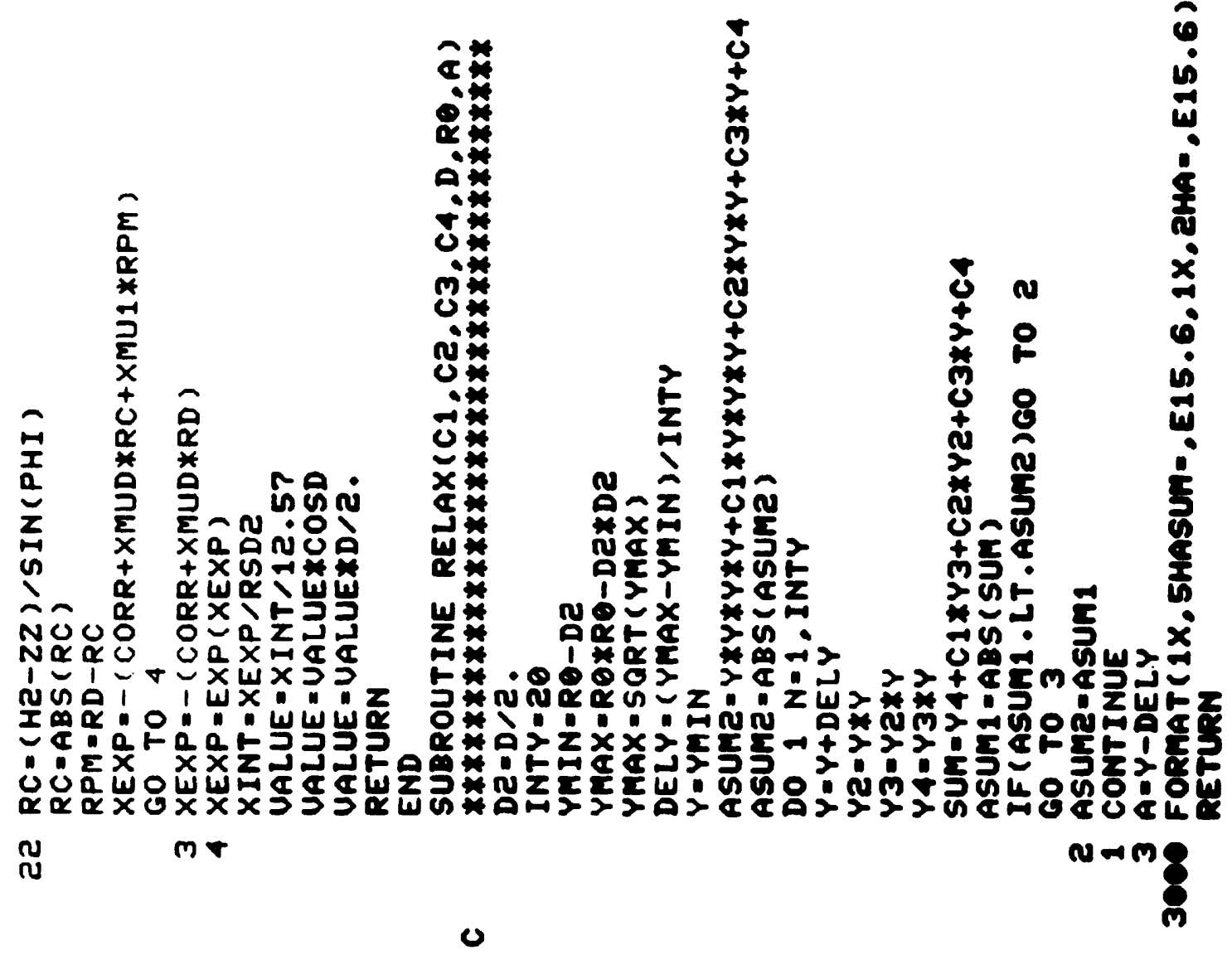



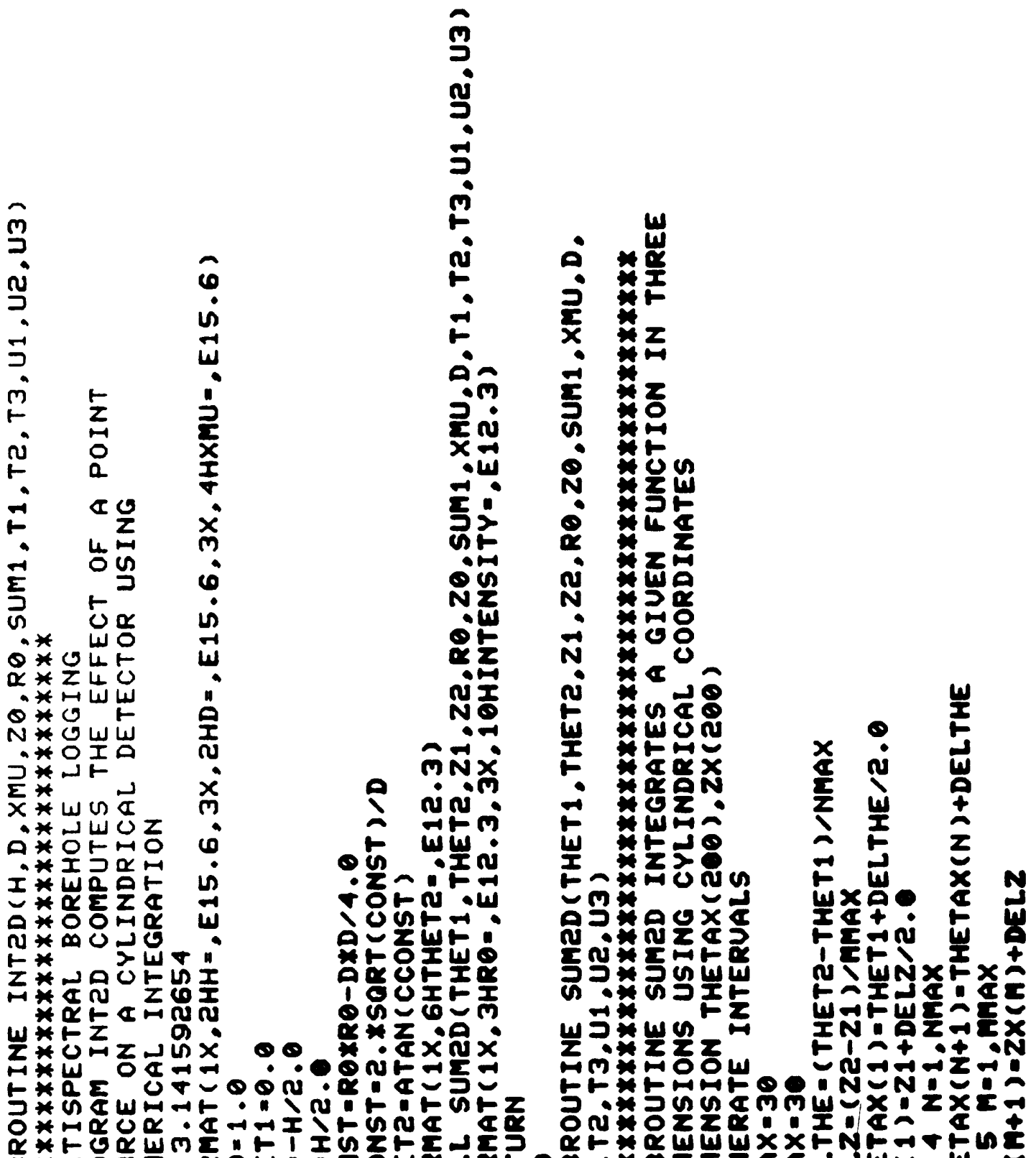

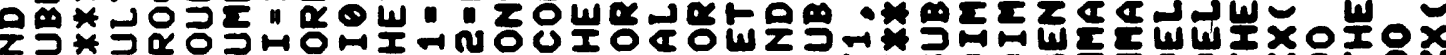

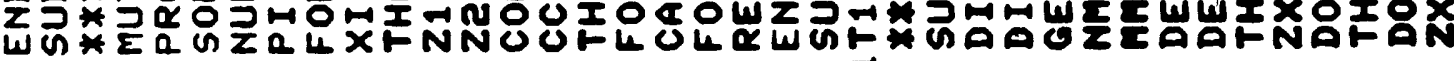

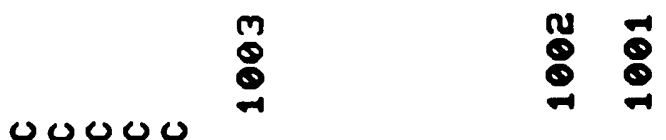




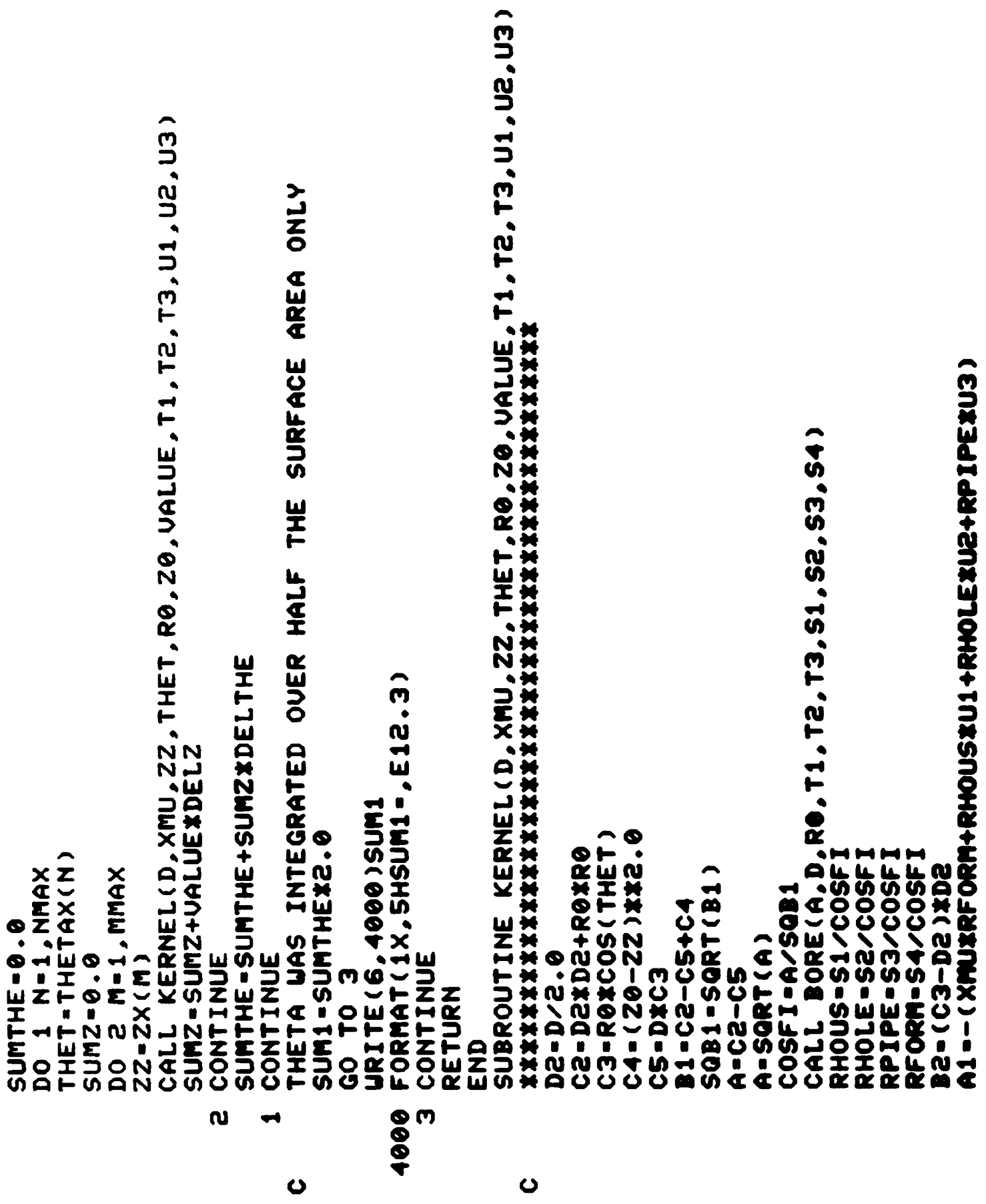




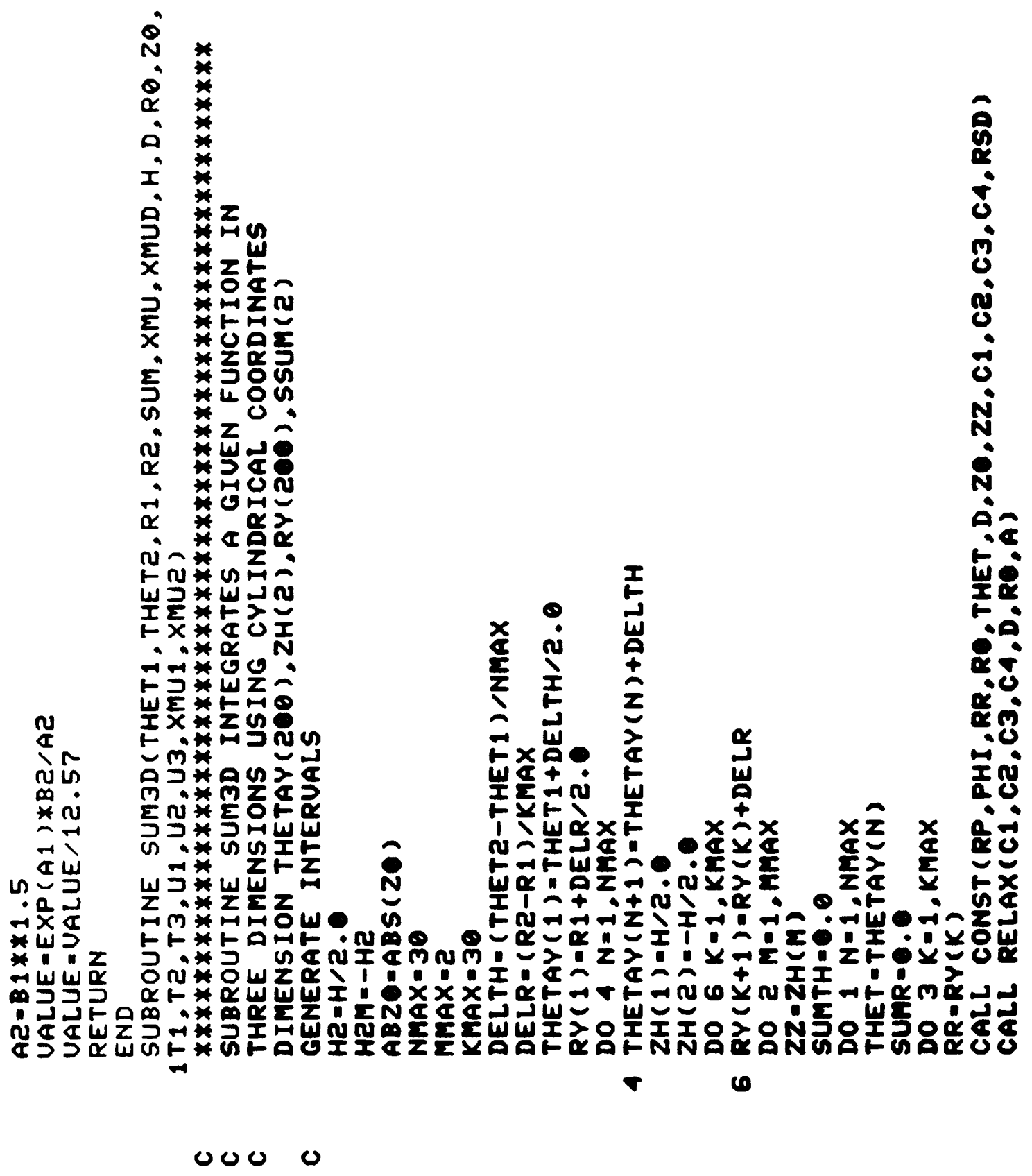




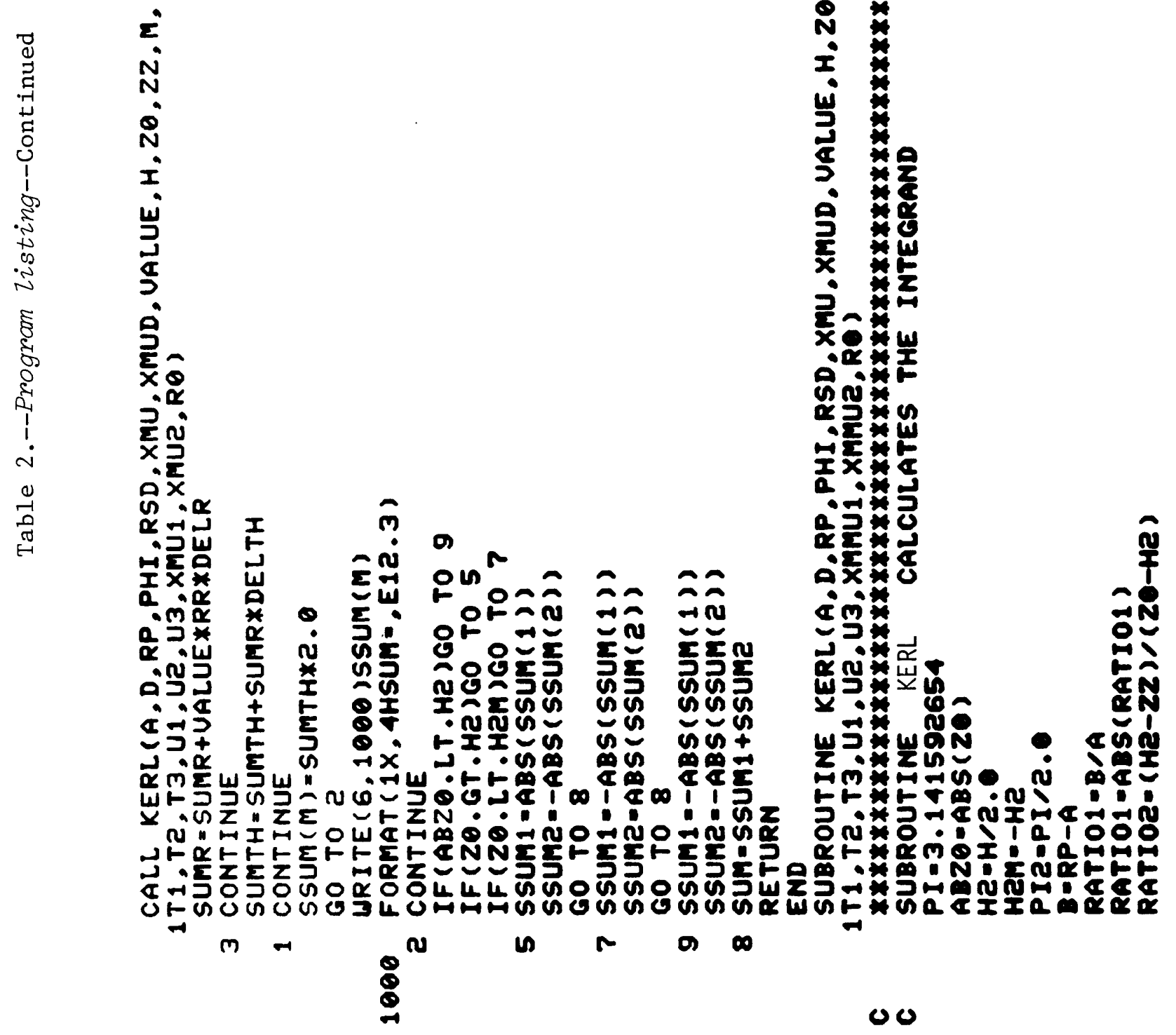




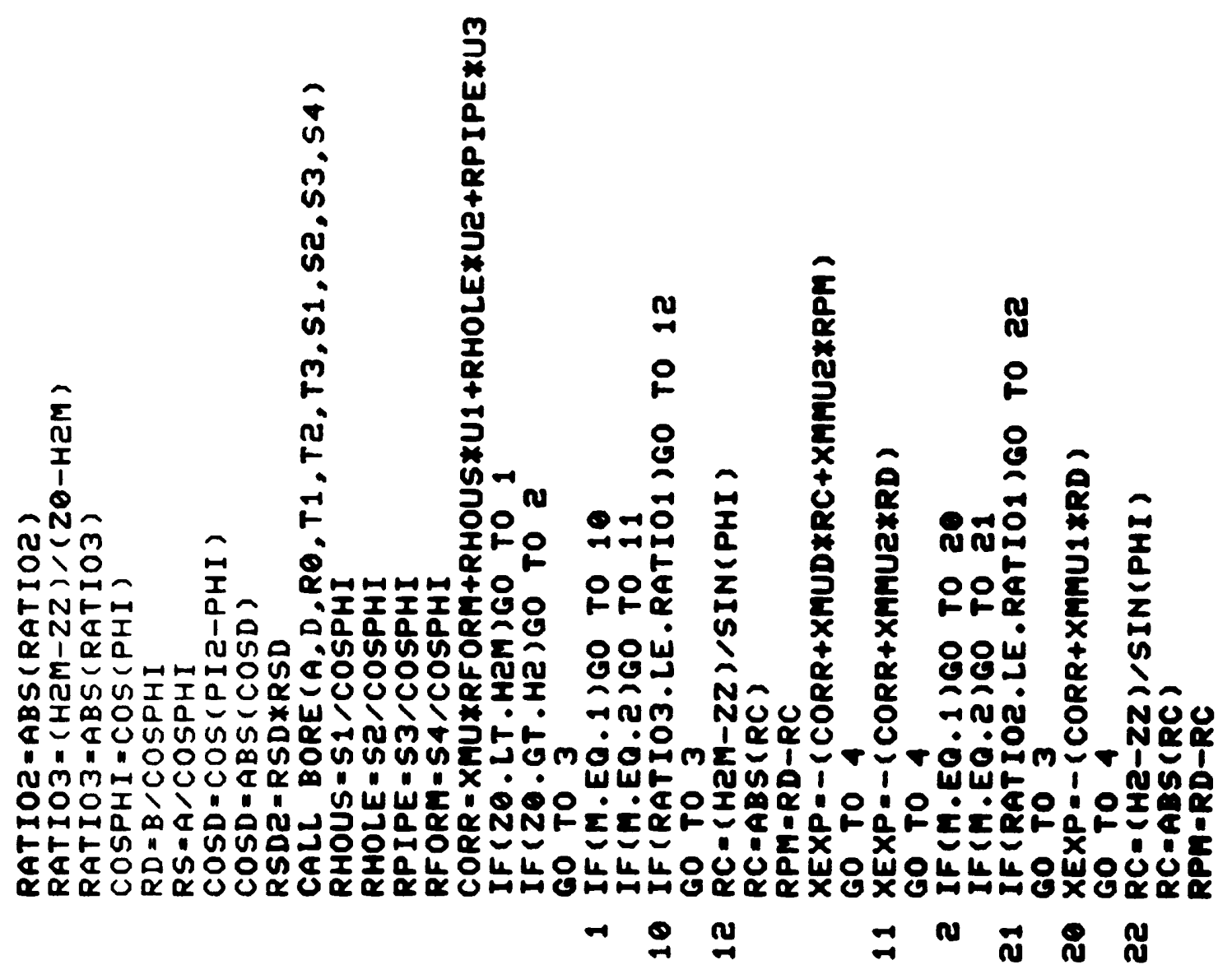


* ना mm

* 안안안

누 웅용요

*ㅜ 엤

i $\quad \sum x \quad \sum x$

山*

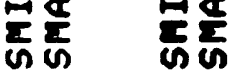

$\sum *$

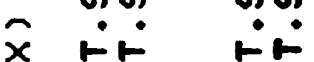

* D כ

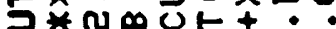

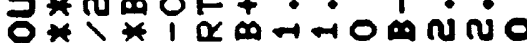

in in

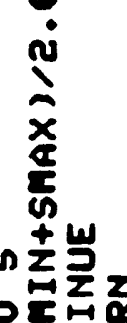

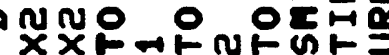

* m n $n$ "

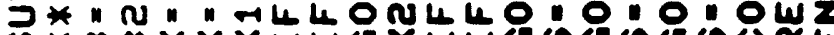

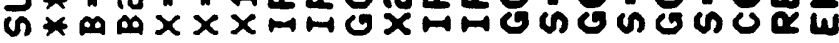

$\sim N \rightarrow m i n$

0 